\title{
APPLICABILITY OF A PRISMATIC PANEL TO OPTIMIZE WINDOW SIZE AND \\ DEPTH OF A SOUTH-FACING ROOM FOR A BETTER DAYLIGHT \\ PERFORMANCE
}

\author{
Büşra KÖSE and Tuğçe KAZANASMAZ \\ Izmir Institute of Technology, Department of Architecture \\ Email: fatmabusra.kose@gmail.com,tugcekazanasmaz@iyte.edu.tr
}

\begin{abstract}
This study examines the performance of attached prismatic panels which have shading capability, in a side-lit deep plan room to find out the least possible WWR value in relation to room depth satisfying the required daylight availability. The methodology is based on simulating a base model in Relux and testing it with alternative models composed of incrementally defined WWR and room depth values. In accordance with minimum IES requirements, the most satisfying sDA value was found to be $48.54 \%$ in a room of $12 \mathrm{~m}$ depth with $67 \%$ WWR. An sDA of 51.59\% and 59.26\% was achieved in a room of 9m depth with 43\% WWR and 6m depth with 30\% WWR, respectively. The least ASE values were obtained with the least WWR alternative of $30 \%$ in all room depths. This study presents a new approach with the consideration of innovative daylight redirecting systems to propose revisions for the requirements mentioned in standards about daylight in buildings but based on conventional fenestration systems.
\end{abstract}

Keywords: daylight, prismatic panels, windows, room depth

$\begin{array}{lll}\text { Abbrevations: } & \text { WWR: } & \text { Window-to-wall ratio } \\ & \text { AR: } & \text { Aspect Ratio } \\ & \text { SDA: } & \text { Spatial Daylight Autonomy } \\ \text { ASE: } & \text { Annual Sunlight Exposure } \\ \text { IES: } & \text { Illuminating Engineering Society } \\ \text { IEA: } & \text { International Energy Agency }\end{array}$

\section{INTRODUCTION}

The effective daylit zone is limited to the window edge in a conventional side lighted space with a vertical window; areas further away from the perimeter zone receive considerably lower daylight [1]. Increasing window size to expand the effective daylit zone can contribute small gains in daylight levels at the rear part of the room but causes excessive solar radiation near the window [2]. This disproportional distribution of daylight in space results in thermal 
and visual discomfort in front part of the room while additional support from artificial lighting is required at the back, which means undesirable lighting conditions for the occupants [3]. Therefore, determining appropriate room and window ratio according to climatic conditions is significant terms of visual comfort and energy savings [4]. Especially in hot climatic regions, uniform distribution is required to achieve the desired visual and thermal comfort.

Using conventional solar shading devices, such as roller shades or venetian blinds, reduce the amount of daylight entering into room and worsen the daylight distribution across the space $[5,6]$. Innovative daylighting systems have been proposed to overcome shortcomings of conventional daylighting techniques. Prismatic daylight-redirecting panels, for instance, improve daylight distribution through sun shading and redirection $[7,8]$.

The purpose of the study is primarily to test the performance of attached prismatic panels in defining optimum window size and room geometry when prismatic panels are installed in the side windows. The second aim is to provide sufficient daylight as deeply as possible into the space in every WWR-Room depth design alternatives and preventing excessive direct sunlight which may cause negative impacts on occupants. The climate of Izmir is another significance, meaning that, it would be possible to understand the applicability of a prismatic system in such a geographic and climatic location.

\section{MODELLING THE BASE CASE ROOM}

\subsection{Daylight illuminance and optical material measurements}

The base case is a deep-plan room having dimensions of $6 \mathrm{~m}$ by $12 \mathrm{~m}$ with $3.8 \mathrm{~m}$ height. Its window dimension is $5.5 \mathrm{~m} \mathrm{x} 2.8 \mathrm{~m}$. The daylight illuminance measurements were taken on December 21,2017 , at three times a day $(9.30,12.30,15.30)$ under overcast sky condition. A total of 19 measurement points was located with a $0.6 \mathrm{~m}$ spacing, in the middle line of the room perpendicular to window line. Optical material properties were determined using both a luminance and illuminance meter as in Literature [4]. Reflectance values of walls, ceiling and floor are $0.90,0.85$ and 0.60 respectively. The glazing has a transmittance value of 0.80 .

Verification process included the comparison to determine how well Relux simulation outputs match up with the actual measurement results. The coefficient of determination $\left(\mathrm{R}^{2}\right)$ was calculated to measure the accuracy of the simulation model. They were $0.93,0.99,0.97$ in simulations ran for 9.30, 12.30 and 15.30 respectively, indicating the high accuracy and verification of Relux software. 


\subsection{Prismatic Panel in Relux Model}

Prismatic panels (Siteco 45/45) manufactured by company Siteco[9] were chosen to enhance the daylight quality in interior space. They are in louver form, placed inside the window at slat angle of $45^{\circ}$. Prismatic panels were installed upper part of the window, between $2.00 \mathrm{~m}$ and $3.80 \mathrm{~m}$ above the floor. This position above the eye level prevents potential glare arising from daylight redirection through prismatic panels. The lower part of the window allows view outside. The distance between each panel was set to be $0.30 \mathrm{~m}$. The identical prismatic panels were applied to all room depth-wwr configurations (Fig.2).
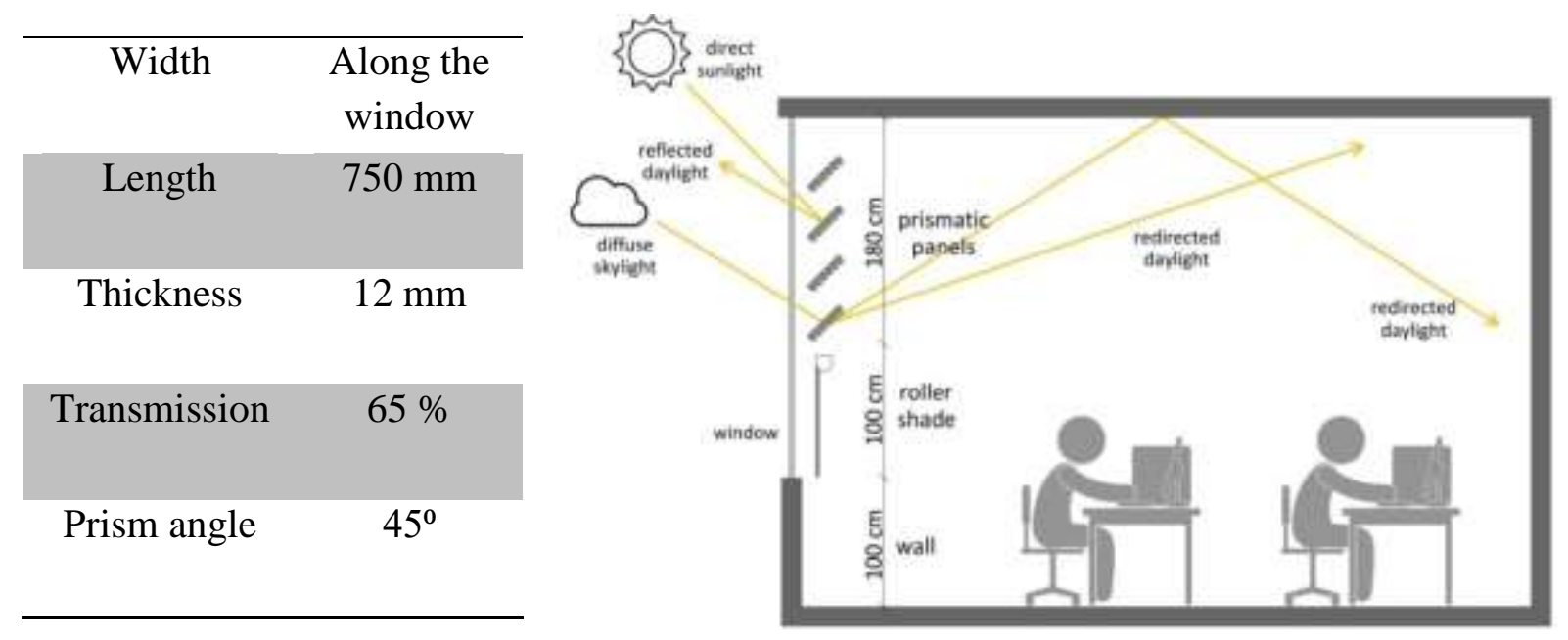

Fig.1. Schematic illustration of prismatic panel principle and application

\subsection{Design Alternatives}

Alternative room depths and window sizes were determined following standards in literature and modeled in Relux. First, limiting room depth for the reference room was determined using the equation described in The British Code BR 8206(Part 2) [10] as:

$$
\frac{\mathrm{L}}{\mathrm{W}}+\frac{\mathrm{L}}{\mathrm{H}_{w}}<\frac{2}{1-\mathrm{R}_{b}}
$$

where $\mathrm{L}$ is the room depth, $\mathrm{W}$ is the room width, $\mathrm{H}_{\mathrm{w}}$ the window head height above floor level and $\mathrm{R}_{\mathrm{b}}$ the average reflectance of surfaces in the rear half of the room.

According to this equation (1), minimum acceptable room depth of the reference room was found as $9 \mathrm{~m}$, indicating that room depth should not exceed this value to avoid gloomy looking and additional electric lighting in the rear half of the room. Taking limiting value into account, three floor aspect ratios of room depth to width were determined as follows:

$\mathrm{AR}=1 \quad$ (when room depth is $6 \mathrm{~m}$, less than limiting value)

$\mathrm{AR}=1.5 \quad$ (when room depth is $9 \mathrm{~m}$, equal to limiting value) 


$$
\mathrm{AR}=2 \quad \text { (when room depth is } 12 \mathrm{~m} \text {, greater than limiting value) }
$$

Since large windows increases exposure to sun and causes excessive heat gain and visual discomfort, the window area of each determined aspect ratio was incrementally reduced as shown in Fig. 2. Starting from the reference case with WWR of $67 \%$, the window width was reduced by $50 \mathrm{~cm}$ from both sides at each stage until minimum acceptable WWR of $30 \%$ (due to British Code BR8206) (11) was achieved.
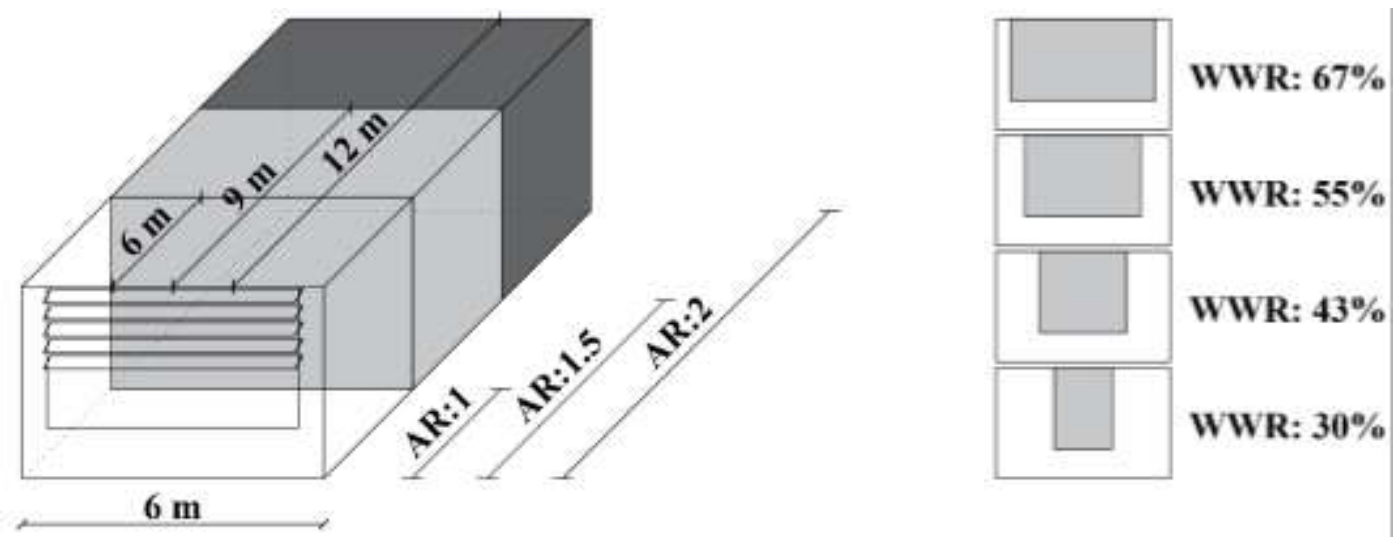

Fig.2. Schematic view of stages in determining aspect ratios and window-to-wall ratios.

The reflectance of walls, ceiling and floor were assigned as 0.50, 0.85, 0.20, according to IEA Task 27 [11]. The measurement points were set to be $75 \mathrm{~cm}$ above the floor, $60 \mathrm{~cm}$ away from the walls surfaces and $60 \mathrm{~cm}$ spacing between each point. Totally 171, 126 and 81 measurement points were determined for the $12 \mathrm{~m}, 9 \mathrm{~m}$ and $6 \mathrm{~m}$ deep room, respectively. Simulations were run on solstice and equinox days at 10:00, 13:00 and 16:00. The 10\% transparent sunshade was considered at the lower part of the window to avoid excessive sunlight exposure since all measurements were carried out under CIE clear sky conditions in a room facing South. In case of overcast sky conditions, additional sunshade would not be necessary, therefore the visual connection with the external environment would be possible.

\section{FINDINGS}

It is expected that the measurement points with illuminance above $300 \mathrm{~lx}$ will be as much as possible, and the measurement points with illuminance above $1000 \mathrm{~lx}$ will be as few as possible. Minimum acceptable floor area of 55\% for SDA and 7\% for ASE according to IES recommendations.

To simplify the calculation, it was found that the illuminance at each measurement point represents what percentage of the annual working hours. For instance, it was assumed that each measurement point simulated in Relux for $21^{\text {st }}$ March at 10:00 represents 180 working hours from 8 am to $11 \mathrm{am}$ in the spring months. It corresponds $7.5 \%$ of total working hours in a year 
(considering 2400 working hours per year). Likewise, calculations at 13:00 and 16:00 represents 240 working hours from 11 am to $15 \mathrm{pm}$ and 180 working hours from $15 \mathrm{pm}$ to 18 pm, respectively. They correspond $10 \%$ and $7.5 \%$ of total working hours in a year, respectively. The same method was applied for $21^{\text {st }}$ June, $23^{\text {rd }}$ September and $21^{\text {st }}$ December. The percentage of annual working hours when illuminance at each measurement point meets or exceeds $300 \mathrm{~lx}$ were determined. Finally, the measurement points that meets or exceeds $300 \mathrm{~lx}$ at least $50 \%$ of working hours per year were marked on working plane, and ratio of these points to the total measurement points were calculated to achieve sDA value. To calculate ASE, measurement points exposing to illuminance over $1000 \mathrm{~lx}$ for more than 250 working hours per year were determined and ratio of these points to the total measurement points were calculated.

Regarding the aspect ratio 2 (12 $\mathrm{m}$ depth), the 67\% WWR was found to be the optimum window size achieving the $50.24 \%$ analysis area with sufficient daylight (illuminance over 300 lx) and $13.01 \%$ analysis area exposed to direct sunlight (illuminance over 1000 lx). Daylight levels across the room were decreased due to shading capability of prismatic panels but still remained at an acceptable level. Regarding the aspect ratio 1.5 (9 $\mathrm{m}$ depth), the percentage of area with illuminance above $300 \mathrm{~lx}$ was almost halved compared to unshaded room and became $50,99 \%$, when the 43\% WWR was applied. Regarding the aspect ratio 1 (6 $\mathrm{m}$ depth), the configuration with $30 \%$ WWR became the optimum solution, receiving the adequate daylight with the percentage floor area of $56.28 \%$ (see Fig.3).

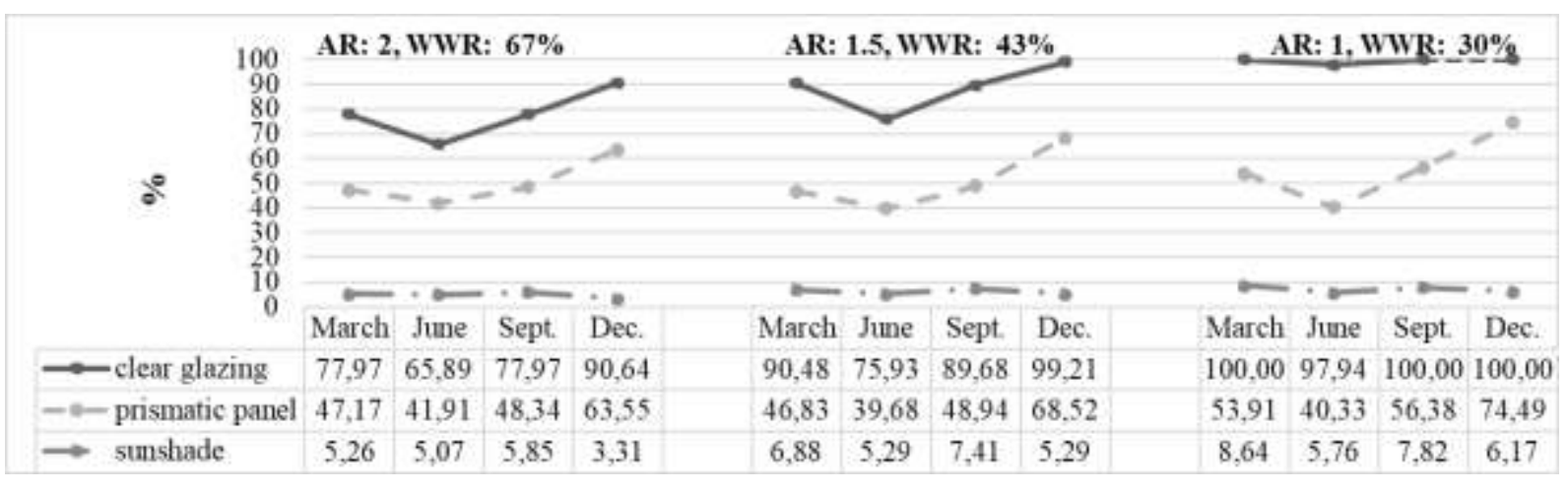

(a) 


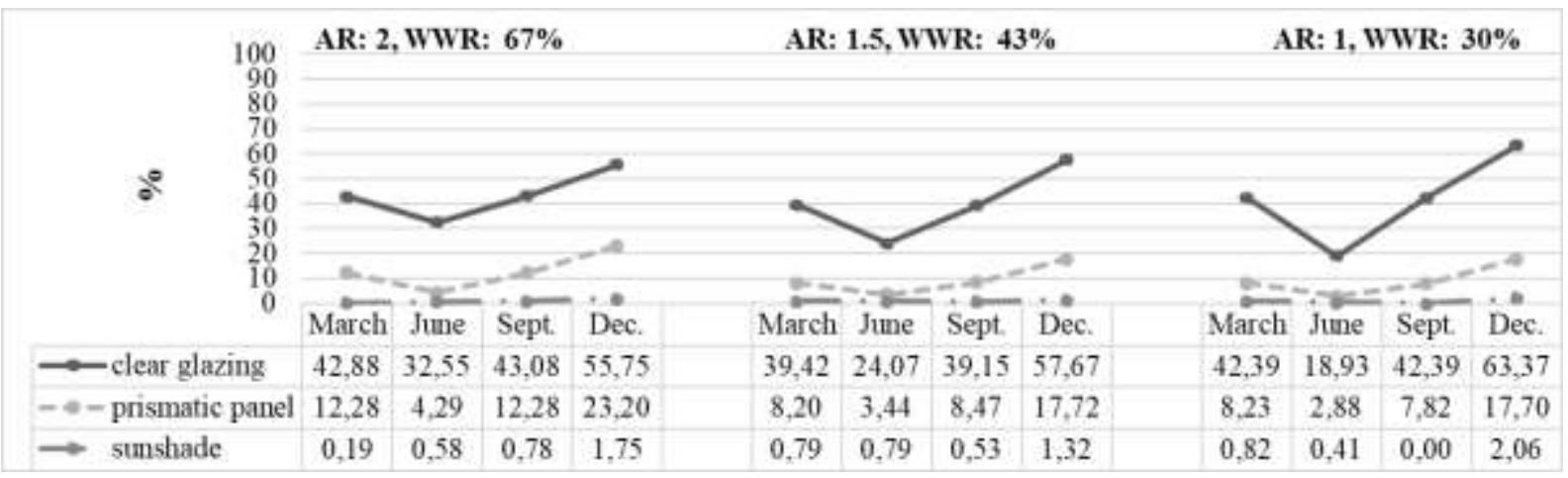

(b)

Fig. 3. Daylighting performance of the rooms with optimum WWR with respect to room depths; illuminance over (a) 300 lx and (b) 1000 lx.

\section{OVERALL ASSESSMENT}

- In winter, daylight penetrated deeper into rooms due to the lower position of the sun and illuminance values increased throughout the room. The prismatic panels were incapable of sun shading during these months and the inclined sun rays passed through between panels led to a considerable increase of illuminance values above $1000 \mathrm{~lx}$. This excessive daylight exposure is also the reason for the high ASE values.

- In summer, the amount of daylight entering the room dropped due to the higher position of the sun. The sun-shading effect of the panels was prominent, since sunlight striking from right angles was reflected by the prism structure. This resulted in a decrease in illuminance values above 1000 lx, which ensures ASE to be within the acceptable range in these months.

- In spring and autumn, the amount of daylight entering the room and the daylight distribution is almost identical. The illuminance values throughout the room are higher than those in summer and lower than those in winter.

- The ratio of the area satisfying $300 \mathrm{~lx}$ was calculated regardless of a specific time fraction for a space, almost corresponds to the estimated sDA value for this space. Contrary to this, the estimated ASE value is considerably greater than the percentage of the area that meets or exceeds illuminance above 1000 lx (see Fig. 4).

- Due to IES requirements, the most satisfying sDA value was found to be $48.54 \%$ in a room of $12 \mathrm{~m}$ depth with $67 \%$ WWR. An sDA of $51.59 \%$ and $59.26 \%$ was achieved in a room of $9 \mathrm{~m}$ depth with $43 \%$ WWR and $6 \mathrm{~m}$ depth with $30 \%$ WWR, respectively.

- The ASE value obtained for each design alternative exceeded the minimum acceptable ASE of $7 \%$ recommended by IES. The closest ASE values were obtained with the least WWR alternative of $30 \%$ in all room depths. This value was $9.94 \%, 13.49 \%$ and $20.99 \%$ in room of $12 \mathrm{~m}, 9 \mathrm{~m}$ and $6 \mathrm{~m}$ depth, respectively. 


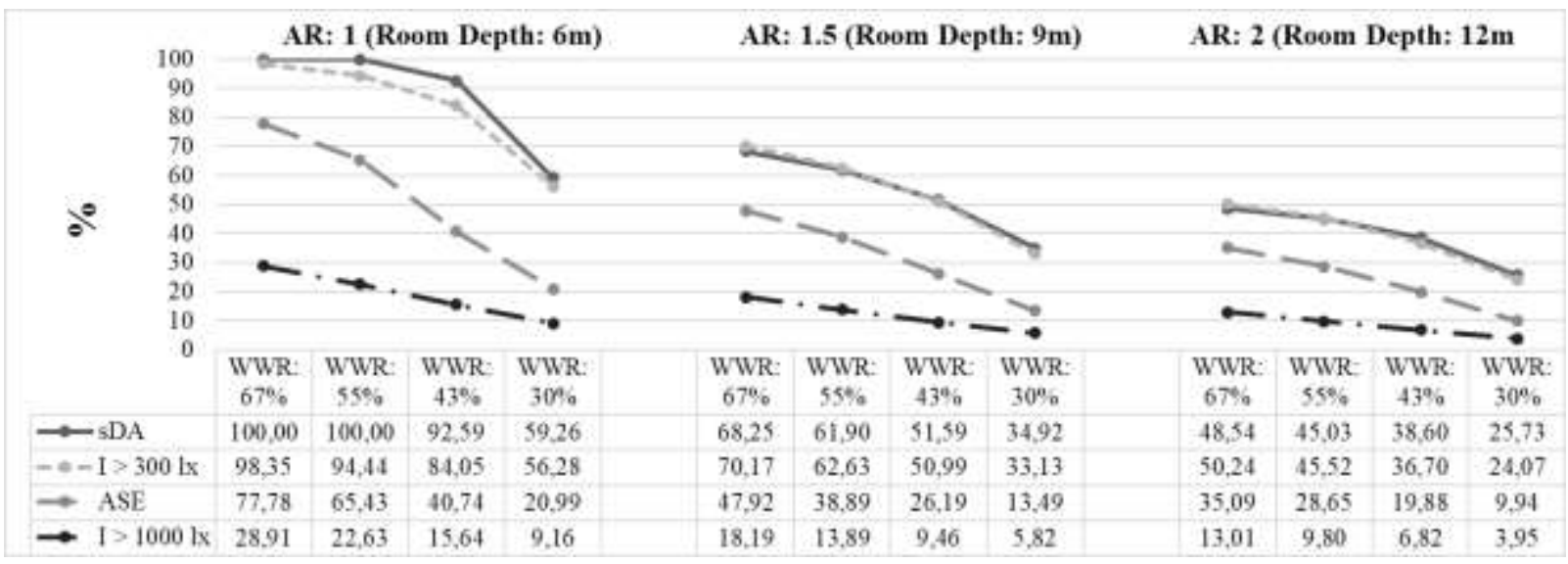

Fig. 4. sDA and ASE values with the percentage of analysis area that meets or exceeds illuminance of $300 \mathrm{~lx}$ and $1000 \mathrm{~lx}$.

\section{CONCLUSION}

This study would make a contribution to literature establishing availability of the 'useful' daylight, i.e. daylight without over-exposure, in side lighted rooms in terms of improving visual performance, and thus motivation, productivity and well-being of occupants. The current daylighting standards and related previous studies in literature include required window sizes for room geometries, but these are restricted to conventional fenestration systems. However, this study emphasizes that a clear glazing without any daylighting system is inadequate to meet the visual performance requirements of the spaces used mostly during the daytime such as educational and office buildings. It has been shown that it is possible to control and use daylight efficiently with the application of advanced daylighting systems such as prismatic panels on vertical windows. The consideration of such systems simultaneously with the facade openings in the early design stages is more favourable in terms of avoiding problems related to the amount and distribution of daylight. Therefore, this study suggests new optimal WWR in relation with varying room depths when prismatic panels attached in side windows and recommends rethinking of daylighting requirements mentioned in current daylighting standards.

\section{REFERENCES}

1. Reinhart, C. F. "A simulation-based review of the ubiquitous window-head-height to daylit zone depth rule-of-thumb," in Proceedings of the Ninth International IBPSA Conference Montréal, Canada, Agust 15-18, 2005. 
2. Kim, J., Wineman J. Are windows and views really better? A quantitative analysis of the economic and psychological value of views. New York: Lighting Research Center, Rensselaer Polytechnic Institute, 2005.

3. Bayram, G., Kazanasmaz, T. Simulation based retrofitting of an educational building in terms of optimum shading device and energy efficient lighting criteria. Light and Engineering, 2016. V24, No.2, pp. 45-55.

4. Littlefair, P.J. Solar shading of buildings. London: Construction Research Communications by permission of Building Research Establishment, 1999.

5. Laura, B., Marino, C., Minichiello, F., Pedace, A. An overview on solar shading systems for buildings. Energy Procedia, 2014. V62, pp. 309-317.

6. Ünver, R. Prediction of interior daylight availability for external obstructions in Istanbul. Light and Engineering, 2009. V17, No.3, pp. 54-64.

7. Ruck, N., Aschehoug, Ø., Aydinli, S., Christoffersen, J., Courret, G., Edmonds, I., Jakobiak, R., Kischkowweit-Lopin, M., Klinger, M., Lee, E., Michel, L., Scartezzini, J-L, \& Selkowitz, S. Daylight in Buildings-A source book on daylighting systems and components. Lawrence Berkeley National Laboratory: Washington, DC, USA, 2000.

8. Kazanasmaz, T., Firat Örs, P. Comparison of advanced daylighting systems to improve illuminance and uniformity through simulation modeling. Light and Engineering, 2014. V22, No.3, pp.56-66.

9. Siteco Stationary and Movable Prism Systems. [Online] Available from: https://www.siteco.com/en/home [Accessed August 2017].

10. British Standards Institution. BS 8206-2:1992. Code of Practice for daylighting. London: BSI, 1992.

11. van Dijk, D., Platzer, W.J. Reference office for thermal, solar and lighting calculations. IEA-SHC Task 27, 2001.

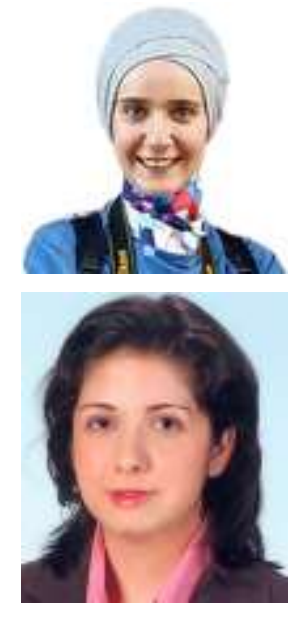

Büşra Köse, MSc, PhD candidate at Department of Architecture from Izmir Institute of Technology. She got her Master's degree in June, 2019. She is interested in lighting design and energy efficiency in buildings.

Tuğçe Kazanasmaz, Prof. Dr., held a Doctor of Philosophy in Building Science from Middle East Technical University (METU). She has 19 years academic experience in architectural lighting, building physics and energy efficient design. At present, she is a Professor in the Department of Architecture in İzmir Institute of Technology, Turkey. 